\title{
Fixed-bed Column Study for Adsorption of Cadmium on Oil Palm Shell-derived Activated Carbon
}

\author{
Chai Ping Ling ${ }^{1}$, Ivy Ai Wei Tan ${ }^{2, *}$, Leonard Lik Pueh Lim $^{3}$ \\ ${ }^{1,2}$ Department of Chemical Engineering and Energy Sustainability, \\ Universiti Malaysia Sarawak, 94300 Kota Samarahan, Malaysia. \\ ${ }^{3}$ Department of Civil Engineering, Universiti Malaysia Sarawak, \\ 94300 Kota Samarahan, Malaysia.
}

\begin{abstract}
The spread of heavy metal pollution in the environment can lead to the contamination of crops and water for consumption. An approach to control the spread of groundwater pollution is by using a permeable reactive barrier with granular activated carbon. In this study, the adsorption of Cd(II) ions was conducted in a continuous flow fixed-bed column by using oil palm shell-derived activated carbon. The activated carbon column performance was evaluated by manipulating the activated carbon bed height, cadmium solution flow rate and influent concentration. The increase in bed height increased the amount of adsorbent used, thus increasing the total removal of $C d(I I)$ and prolonged the lifespan of the activated carbon column. However, the increase in flow rate and influent concentration resulted in the shortened lifespan of the column. The column system with a bed height of $5.5 \mathrm{~cm}$, flow rate of $2.0 \mathrm{~mL} / \mathrm{min}$ and $200 \mathrm{mg} / \mathrm{L}$ influent concentration showed the best Cd(II) uptake performance in this study. The column performance were best fitted to the Thomas model and Yoon-Nelson model for the longest bed depth of $5.5 \mathrm{~cm}$, all flow rates studied and highest influent concentration of $200 \mathrm{mg} / \mathrm{L}$, with correlation coefficient greater than 0.95 .
\end{abstract}

Keywords: Adsorption, agriculture waste-derived adsorbent, breakthrough curve, continuous flow .

\section{Introduction}

Most environmental pollution occurs due to the negligence of the operator in controlling their effluent discharge at source despite the known impact and discharge regulation - a pollutant of global concern is heavy metal. The spread of heavy metal in the environment, especially groundwater, can lead to the contamination of crops and water for consumption. Heavy metal spreads faster in acidic ground due to its solubility and this requires longer duration and more tedious effort for the cleanup. Passive approach such as permeable reactive barrier with adsorbent $[1,2]$ has been applied to control the spread of pollutants in the ground by adsorbing the pollutants from migrating further. Activated carbon has been proven to be a flexible wastewater treatment technique due to the high adsorptive capacity and versatility. Currently, the production of activated carbon from renewable and low cost materials especially from agricultural wastes has become the focus of attention of numerous researchers because the conventional raw materials for producing activated carbons are costly. Therefore, the production of activated carbon from agricultural wastes is more economical and friendly to the environment. Malaysia has around 4.7 million hectares of oil palm plantation [3]. As one of the world's largest producers of palm oil, Malaysia palm oil industry generates a vast amount of palm oil wastes, such as empty fruit bunch, fiber, wet shell, palm kernel, fronds and trunks. Oil palm shell is a highly carbonaceous material and thus the conversion of oil palm shell into activated carbon

\footnotetext{
* Corresponding author. Tel.: +6082-583312; fax: +6082-583410

E-mail address: awitan@unimas.my
}

Manuscript History:

Received 22 August, 2016, Revised 11 September, 2016, Accepted 23 September, 2016, Published 30 September, 2016

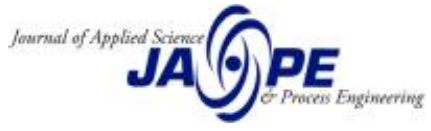


is feasible. The cost of activated carbon can be reduced besides minimizing the amount of wastes to be disposed.

Although activated carbon adsorption is effective for removing heavy metals from water, there are limited adsorption studies being conducted in fixed-bed columns to simulate the performance of activated carbon in the form of a barrier. Therefore, this study focus on the continuous fixed-bed adsorption of cadmium, Cd (II) as the batch adsorption study conducted by Chan [4] had provided elementary information concerning the $\mathrm{Cd}$ (II) removal process. It has been reported that the activated carbon prepared using $\mathrm{H}_{3} \mathrm{PO}_{4}$ treatment with microwave-induced activation is effective for adsorption of $\mathrm{Cd}$ (II) ions, with adsorption capacity of $78.73 \mathrm{mg} / \mathrm{g}$. Batch system however provides effective application for a short optimum period at a single time and requires a large amount of adsorbent for a large volume of effluent from the economic point of view. Meanwhile, for the column system, the application is more practical and economical for industrial scale as the operation is conducted continuously and the process is controllable. Besides, the information of the breakthrough curve can be used to determine a rational scale of an adsorption column for industrial scale. The optimum conditions determined from Chan [4] for synthesis of the activated carbon using 1:2 precursor: $\mathrm{H}_{3} \mathrm{PO}_{4}$ impregnation ratio, $700 \mathrm{~W}$ microwave power and 5 minutes irradiation time was further applied in this continuous fixed-bed adsorption study to identify the feasibility of using the prepared activated carbon under loading with Cd (II) ions continuously.

The aim of this study is to investigate the feasibility of the oil palm shell-derived activated carbon prepared using $\mathrm{H}_{3} \mathrm{PO}_{4}$ treatment and microwave-induced activation in removing $\mathrm{Cd}$ (II) ions using fixed-bed adsorption column at different activated carbon bed height, Cd (II) solution flow rate and influent concentration. The experimental data were then fitted into different column adsorption models, which were Thomas model, Yoon-Nelson model, Adam-Bohart model and Bed Depth Service Time (BDST) model to evaluate the adsorption capacity and performance of the activated carbon column.

\section{Materials and methods}

\subsection{Adsorbent preparation}

The precursor was first rinsed with water to remove the dirt on the surface. After that, in order to remove oil residue and other impurities, it was soaked in n-hexane. The sample was then dried in an oven at $120^{\circ} \mathrm{C}$ for 24 hours to remove the moisture content. The dried precursor was subsequently crushed and sieved to obtain $1 \mathrm{~mm}$ particle size [4]. The activated carbon was prepared by using chemical activation combined with microwave-induced heating. Chemical activation which consisted of phosphoric acid $\left(\mathrm{H}_{3} \mathrm{PO}_{4}\right)$ with 1:2 (w/w) impregnation ratio, $700 \mathrm{~W}$ microwave power and irradiation time of 5 minutes was used to prepare the activated carbon.

\subsection{Chemicals and reagents}

The chemicals used throughout this study were of analytical reagent grade. The stock solution of $1000 \mathrm{mg} / \mathrm{L} \mathrm{Cd}$ (II) was prepared by dissolving $\mathrm{Cd}\left(\mathrm{NO}_{3}\right)_{2} .4 \mathrm{H}_{2} \mathrm{O}$ in $1.0 \mathrm{~L}$ of deionized water and further diluted to the desired concentration with deionized water.

\subsection{Column experiments}

For the column experiments, a glass column (Ace Glass, Inc.) with inner diameter of $1.0 \mathrm{~cm}$ and length of $18 \mathrm{~cm}$ was used. During the adsorption process, the bottom of the column was blocked with a plastic mesh and polyethylene wool to prevent loss of adsorbent. A peristaltic pump (BT100-2J, Baoding Longer Precision Pump Co., Ltd.) was used to feed the Cd (II) solution into the column. The 
schematic diagram of the continuous packed-bed column system is shown in Figure 1. A known weight of activated carbon was packed into the column according to the desired bed height. The activated carbon packed in the column was wetted with deionized water in upward flow direction before the experiment was started. This was to withdraw the trapped air between the particles inside the column. Then, the Cd (II) working solutions were fed upward into the column by a peristaltic pump continuously $[5,6]$. The effluent was collected at regular time intervals, and the samples were filtered and analyzed for the cadmium concentration using an atomic absorption spectrophotometer (AAS).

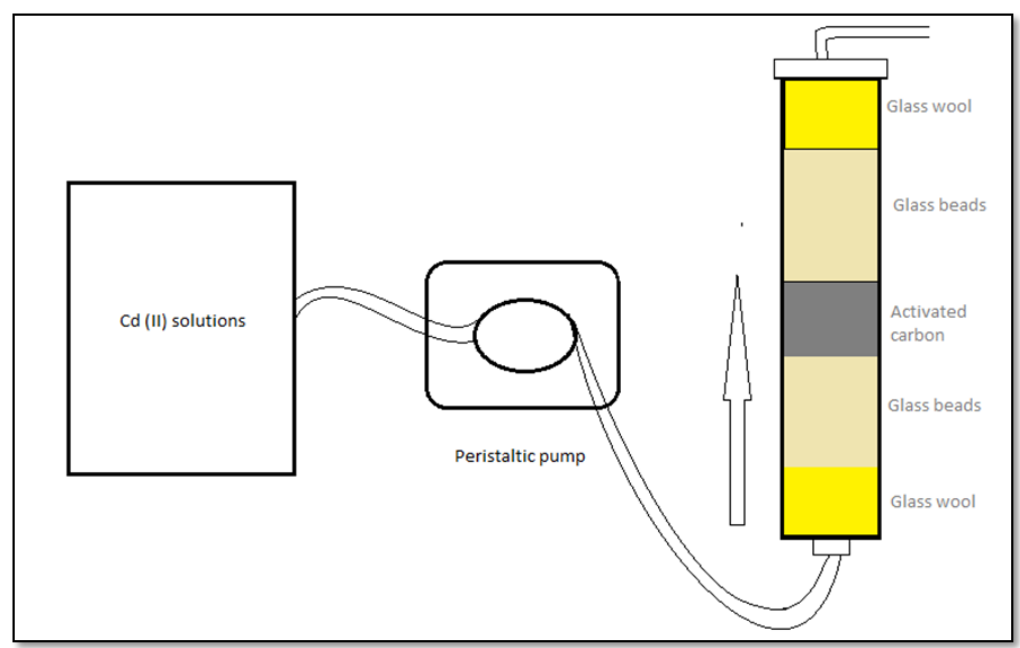

Figure 1. Schematic diagram of continuous flow packed-bed column system

\subsubsection{Effect of bed height}

The activated carbon amounts were varied according to the desired bed height and packed in the column for the evaluation of the effect of the bed height [6] on the adsorption performance. The bed height was varied at $3.0 \mathrm{~cm}, 4.0 \mathrm{~cm}$ and $5.5 \mathrm{~cm}(1.5 \mathrm{~g}, 2.1 \mathrm{~g}$ and $3.0 \mathrm{~g}$ of activated carbon, respectively). The influent concentration and the flow rate of Cd (II) solutions were fixed at $200 \mathrm{mg} / \mathrm{L}$ and $3.0 \mathrm{~mL} / \mathrm{min}$, respectively. The collection of effluent for analysis was at regular time intervals until the breakthrough curve was obtained.

\subsubsection{Effect of flow rate}

The contact period between the adsorbate and adsorbent affects the removal of metal ions by the adsorbent. In relation to this scenario, the bed height and influent concentration were kept constant at $5.5 \mathrm{~cm}$ and $200 \mathrm{mg} / \mathrm{L}$, respectively while manipulating the flow rate at $2.0,3.0$ and $5.0 \mathrm{~mL} / \mathrm{min}$. At regular time intervals, the effluent was collected for cadmium analysis.

\subsubsection{Effect of influent concentration}

For the evaluation of the effect of influent concentration, the stock solutions were diluted into different concentrations of $100 \mathrm{mg} / \mathrm{L}, 150 \mathrm{mg} / \mathrm{L}$ and $200 \mathrm{mg} / \mathrm{L}$. The influent flow rate and the bed height were fixed at $3.0 \mathrm{~mL} / \mathrm{min}$ and $5.5 \mathrm{~cm}$, respectively in this case. The effluent was similarly collected for cadmium analysis at regular time intervals. 


\subsection{Mathematical description and adsorption modeling of fixed-bed column studies}

The breakthrough curve of the continuous fixed-bed system is used to evaluate the column performance. Generally, the breakthrough curve is described by $\mathrm{C}_{\text {eff }} / \mathrm{C}_{\mathrm{o}}$, in which $\mathrm{C}_{\text {eff }}$ and $\mathrm{C}_{\mathrm{o}}$ represent the effluent and influent concentrations, respectively. The adsorbed metal ion concentrations in the column are observed by a plot of the adsorbed metal concentration, $\mathrm{C}_{\mathrm{ad}}$ (1) or normalized concentration defined as the ratio of effluent metal concentration to influent concentration $\left(\mathrm{C}_{\text {eff }} / \mathrm{C}_{\mathrm{o}}\right)$ as a function of time or volume of effluent $\left(\mathrm{V}_{\text {eff }}\right)$, as shown in (2) [6].

$$
\begin{aligned}
& \mathrm{C}_{\mathrm{ad}}=\text { Inlet concentration }\left(\mathrm{C}_{\mathrm{o}}\right)-\text { Outlet concentration }\left(\mathrm{C}_{\mathrm{eff}}\right) \\
& \mathrm{V}_{\text {eff }}(\mathrm{mL})=\mathrm{Qt}_{\text {total }}
\end{aligned}
$$

where $\mathrm{Q}=$ Volumetric flow rate $(\mathrm{mL} / \mathrm{min})$

$\mathrm{t}_{\text {total }}=$ Total flow time $(\mathrm{min})$

The adsorbed metal ion $\left(\mathrm{q}_{\text {total }}\right)$ by the column can be obtained by integrating the plot of adsorbed concentration $\left(\mathrm{C}_{\mathrm{ad}}\right)$ versus the flow time $(\mathrm{t})$, represented by the area $(\mathrm{A})$ under the integrated plot. It is substituted in (3) to determine $\mathrm{q}_{\text {total. }}$.

$$
q_{\text {total }}(m g)=\frac{Q A}{1000}=\frac{Q}{1000} \int_{t=0}^{t=t_{\text {total }}} C_{a d} d t
$$

The total amount of metal ions delivered to the column system ( $\left.\mathrm{m}_{\text {total }}\right)$ is obtained from (4).

$$
m_{\text {total }}(m g)=\frac{c_{0} Q t_{\text {total }}}{1000}
$$

The column performance can be evaluated by the percentage of total metal ions removal, as shown in (5).

$$
\text { Total removal of metal ions }(\%)=\frac{q_{\text {total }}}{m_{\text {total }}} \times 100
$$

The equilibrium adsorption, which is also known as the column maximum capacity is also determined from the column data to obtain the adsorption capacity of adsorbent, as expressed in (6).

$$
q_{e q}\left(\frac{m g}{g}\right)=\frac{q_{\text {total }}}{x}
$$

where $\mathrm{X}$ is the unit mass of adsorbent packed in the column.

At the equilibrium, the unadsorbed metal concentration in the continuous flow system is evaluated, as given in (7).

$$
C_{e q}\left(\frac{m g}{L}\right)=\frac{m_{\text {total }}-q_{\text {total }}}{V_{\text {eff }}} \times 1000
$$

There are four types of adsorption modeling which are commonly used to study fixed-bed column system, namely Thomas model, Yoon-Nelson model, Adam-Bohart model and Bed Depth Service Time (BDST) model, which are represented by (8), (9), (10), and (11), respectively.

$$
\ln \left[\frac{C_{0}}{c_{\mathrm{t}}}-1\right]=\frac{k_{T h} q_{0} m}{Q}-k_{T h} q_{O} t
$$




$$
\begin{aligned}
& \ln \left[\frac{c_{\mathrm{t}}}{c_{0}-c_{\mathrm{t}}}\right]=k_{Y N} t-\tau k_{Y N} \\
& \ln \left[\frac{C_{\mathrm{t}}}{c_{0}}\right]=k_{A B} C_{O} t-\frac{k_{A B} N_{O} Z}{U_{O}} \\
& \frac{c}{c_{O}}=\frac{1}{1+\exp \left[k_{B D S T} c_{O}\left(\frac{N_{O}}{C_{O} g} L-t\right)\right]}
\end{aligned}
$$

where

$\begin{array}{lll}\mathrm{C}_{\mathrm{O}} & - & \text { Inlet concentration } \\ \mathrm{C}_{\mathrm{t}} & - & \text { Outlet metal concentration at time t } \\ \mathrm{k}_{\mathrm{AB}} & - & \text { Adam-Bohart kinetic constant } \\ \mathrm{k}_{\mathrm{BDST}} & - & \text { Adsorption rate constant } \\ \mathrm{k}_{\mathrm{Th}} & - & \text { Thomas kinetic coefficient } \\ \mathrm{k}_{\mathrm{YN}} & - & \text { Yoon-Nelson rate constant } \\ \mathrm{L} & - & \text { Bed height } \\ \mathrm{m} & - & \text { Mass of adsorbent in column } \\ \mathrm{N}_{\mathrm{O}} & - & \text { Saturation concentration } \\ \mathrm{N}_{\mathrm{O}} & - & \text { Biosorption capacity of the bed (BDST model) } \\ \mathrm{q}_{\mathrm{O}} & - & \text { Maximum solid phase concentration } \\ \mathrm{T} & - & \text { Time } \\ \mathrm{U}_{\mathrm{O}} & - & \text { Linear velocity } \\ \mathrm{Z} & - & \text { Bed depth of column } \\ \tau & - & \text { Time required for } 50 \% \text { of adsorbate breakthrough } \\ \vartheta & - & \text { Linear flow velocity of metal solution through the bed }\end{array}$

\section{Results and discussion}

\subsection{Column studies}

The ratio of effluent cadmium concentration to the influent cadmium concentration $\left(\mathrm{C}_{\text {eff }} / \mathrm{C}_{\mathrm{o}}\right)$ against the flow time $(\mathrm{t})$, which was the breakthrough curve has been plotted in order to study the performance of the activated carbon column at various activated carbon bed height, cadmium solution flow rate and influent concentration.

\subsubsection{Effect of bed height}

The column performance was expressed through the breakthrough curve of the fixed-bed adsorption studies using three different bed heights: $3.0 \mathrm{~cm}, 4.0 \mathrm{~cm}$ and $5.5 \mathrm{~cm}(1.5 \mathrm{~g}, 2.1 \mathrm{~g}$ and $3.0 \mathrm{~g}$ of activated carbon, respectively). The breakthrough curve is shown in Figure 2. The longest bed height of $5.5 \mathrm{~cm}$ showed the slowest breakthrough as compared to the other bed depths of $3 \mathrm{~cm}$ and 4 $\mathrm{cm}$. The increase in bed height considerably affected the column performance by decelerating the exhaustion time. This was due to the activated carbon column which exhausted faster with shorter bed height [6]. According to Lim and Aris [6], the column was able to perform for a longer period without replacing the adsorbent if there was slower exhaustion time of the adsorbent and vice versa. The column breakthrough and the performance of adsorbent bed were greatly influenced by the length of bed height. From Table 1, the total removal percentage of $\mathrm{Cd}$ (II) was found to increase with the increase in adsorbent dosage. The highest percentage of $53.71 \%$ for removal of Cd (II) was obtained by the column with the longest bed height of $5.5 \mathrm{~cm}$. 


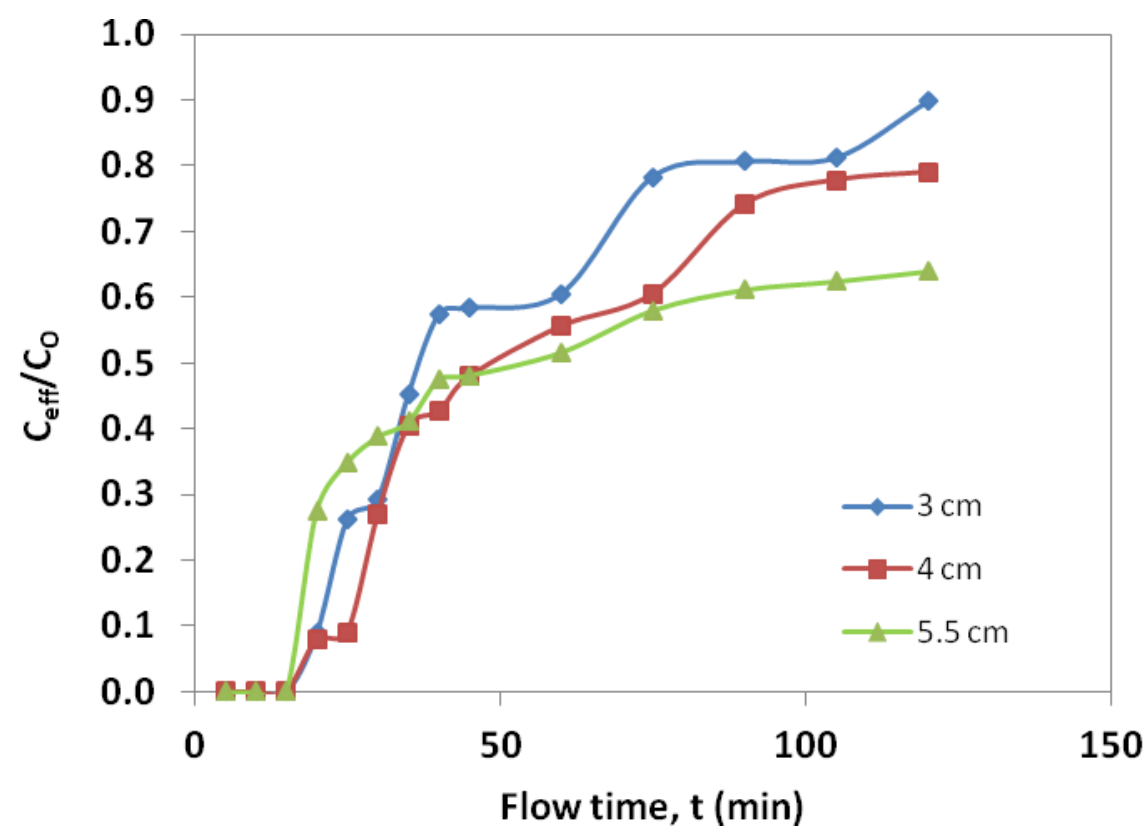

Figure 2. Breakthrough curve for Cd (II) adsorption on prepared AC at different bed heights (flow rate $=3.0 \mathrm{~mL} / \mathrm{min}$, influent concentration $=200 \mathrm{mg} / \mathrm{L}$ )

Table 1. Mathematical description of column parameters

\begin{tabular}{cccccccc}
\hline $\begin{array}{c}\text { Bed } \\
\text { Height } \\
(\mathbf{c m})\end{array}$ & $\begin{array}{c}\mathbf{C}_{\mathbf{0}} \\
(\mathbf{m g} / \mathbf{L})\end{array}$ & $\begin{array}{c}\mathbf{Q} \\
(\mathbf{m L} / \mathbf{m i n})\end{array}$ & $\begin{array}{c}\mathbf{q}_{\text {total }} \\
(\mathbf{m g})\end{array}$ & $\begin{array}{c}\mathbf{m}_{\text {total }} \\
(\mathbf{m g})\end{array}$ & $\begin{array}{c}\text { Total } \\
\text { Removal } \\
(\mathbf{\%})\end{array}$ & $\begin{array}{c}\mathbf{q}_{\text {eq }} \\
(\mathbf{m g} / \mathbf{g})\end{array}$ & $\begin{array}{c}\mathbf{C}_{\text {eq }} \\
(\mathbf{m g} / \mathbf{L})\end{array}$ \\
\hline 3.0 & 200 & 3 & 33.24 & 72 & 46.16 & 22.16 & 107.68 \\
4.0 & 200 & 3 & 36.43 & 72 & 50.59 & 17.35 & 98.81 \\
5.5 & 200 & 3 & 38.67 & 72 & 53.71 & 12.89 & 92.59 \\
5.5 & 200 & 2 & 31.24 & 48 & 65.08 & 10.41 & 69.83 \\
5.5 & 200 & 3 & 37.54 & 72 & 52.15 & 12.52 & 95.70 \\
5.5 & 200 & 5 & 46.24 & 120 & 38.53 & 15.41 & 122.94 \\
5.5 & 100 & 3 & 20.73 & 36 & 57.59 & 6.91 & 42.41 \\
5.5 & 150 & 3 & 36.42 & 54 & 57.45 & 12.14 & 48.82 \\
5.5 & 200 & 3 & 38.32 & 72 & 53.22 & 12.82 & 93.58 \\
\hline
\end{tabular}

\subsubsection{Effect of flow rate}

The effect of the cadmium solution volumetric flow rate on the breakthrough curve was investigated using three different flow rates: $2.0 \mathrm{~mL} / \mathrm{min}, 3.0 \mathrm{~mL} / \mathrm{min}$ and $5.0 \mathrm{~mL} / \mathrm{min}$, with influent cadmium concentration of $200 \mathrm{mg} / \mathrm{L}$ and activated carbon bed height of $5.5 \mathrm{~cm}$. The column system with the slowest flow rate of $2.0 \mathrm{~mL} / \mathrm{min}$ showed a gradual increase in breakthrough curve. Meanwhile, for the highest flow rate of $5.0 \mathrm{~mL} / \mathrm{min}$, its breakthrough curve was seen to increase drastically in the first 10 minutes. Figure 3 shows that the breakthrough time decreased with the increased flow rate. The breakthrough curve became steeper and achieved saturation faster as the flow rate was increased due to the lower contact time between the adsorbate and adsorbent $[7,8]$. According to Sotelo et al. [7], there was not enough time for the adsorption equilibrium to be achieved at higher flow rates. Therefore, the cadmium solution left the column before equilibrium was obtained. 
From Table 1, the slowest flow rate of $2.0 \mathrm{~mL} / \mathrm{min}$ achieved the highest total $\mathrm{Cd}$ (II) removal of $65.08 \%$ in the column system. Besides, this flow rate had the lowest unadsorbed cadmium concentration of the continuous flow system at the equilibrium, which was $69.83 \mathrm{mg} / \mathrm{L}$. On the other hand, the adsorption capacity of the activated carbon increased as the flow rate was increased. The performance of the column was remarkably influenced by the flow rate as it affected the contact time between the adsorbate and adsorbent. The Cd (II) ions had longer time to diffuse through the pores and achieved a higher adsorption capacity when the flow rate was decreased [7, 8]. At higher flow rates, the decrease in liquid film surrounding the adsorbent particles led to the reduction of the boundary layer and the mass transfer resistance in adsorption process [7].

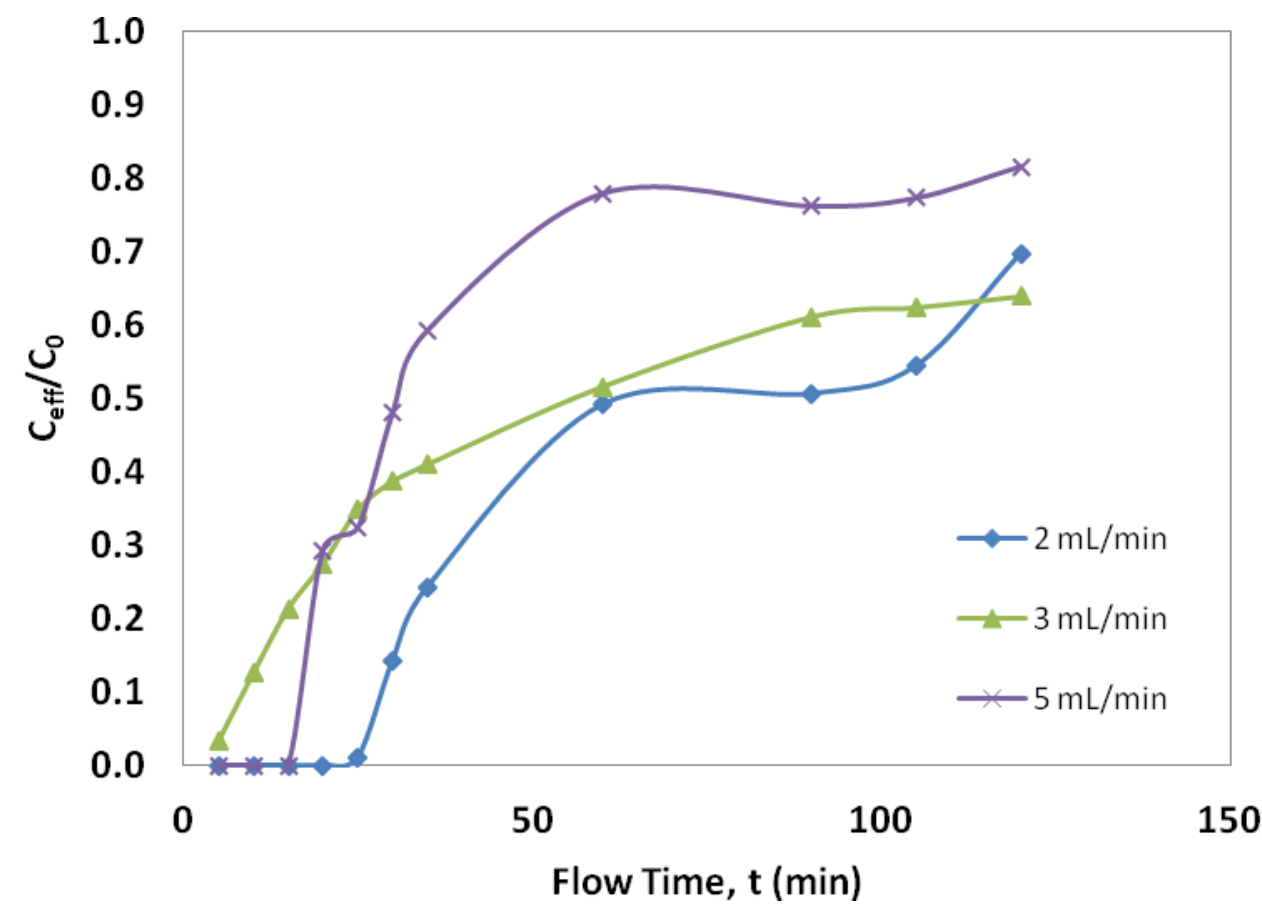

Figure 3. Breakthrough curve for Cd (II) adsorption on prepared $\mathrm{AC}$ at different flow rates (bed height $=5.5 \mathrm{~cm}$, influent concentration $=200 \mathrm{mg} / \mathrm{L}$ )

\subsubsection{Effect of influent concentration}

The effect of the Cd (II) influent concentration on the breakthrough curve was studied by varying the influent concentration at $100 \mathrm{mg} / \mathrm{L}, 150 \mathrm{mg} / \mathrm{L}$ and $200 \mathrm{mg} / \mathrm{L}$, with a constant flow rate and bed height of $3 \mathrm{~mL} / \mathrm{min}$ and $5.5 \mathrm{~cm}$, respectively. From Figure 4, the lowest influent concentration of $100 \mathrm{mg} / \mathrm{L}$ showed the steepest slope of the breakthrough curve and closed to complete saturation after $120 \mathrm{~min}$. A steeper breakthrough slope indicated that the activated carbon was exhausted more quickly, therefore $\mathrm{C}_{\mathrm{eff}} / \mathrm{C}_{0}$ increased faster. The gradual increase in $\mathrm{C}_{\mathrm{eff}} / \mathrm{C}_{0}$ at higher influent concentration indicated partial saturation of the activated carbon active sites during the experiment. The partial saturation showed that some Cd (II) ions were not adsorbed by the activated carbon as they flowed through the activated carbon packing. However, in terms of Cd (II) uptake, $200 \mathrm{mg} / \mathrm{L}$ showed the highest $\mathrm{q}_{\mathrm{eq}}$ value of $12.82 \mathrm{mg} / \mathrm{g}$, as shown in Table 1, in which the Cd (II) ions uptake increased with the increase of influent concentration. This was due to the probability of collusion between the $\mathrm{Cd}$ (II) ions and the adsorbent increased while increasing the influent $\mathrm{Cd}$ (II) concentration [9]. A decrease in influent concentration gave an extended breakthrough curve due to the fact that lower 
concentration gradient caused a slower transport due to a decrease in diffusion coefficient or mass transfer coefficient [10].

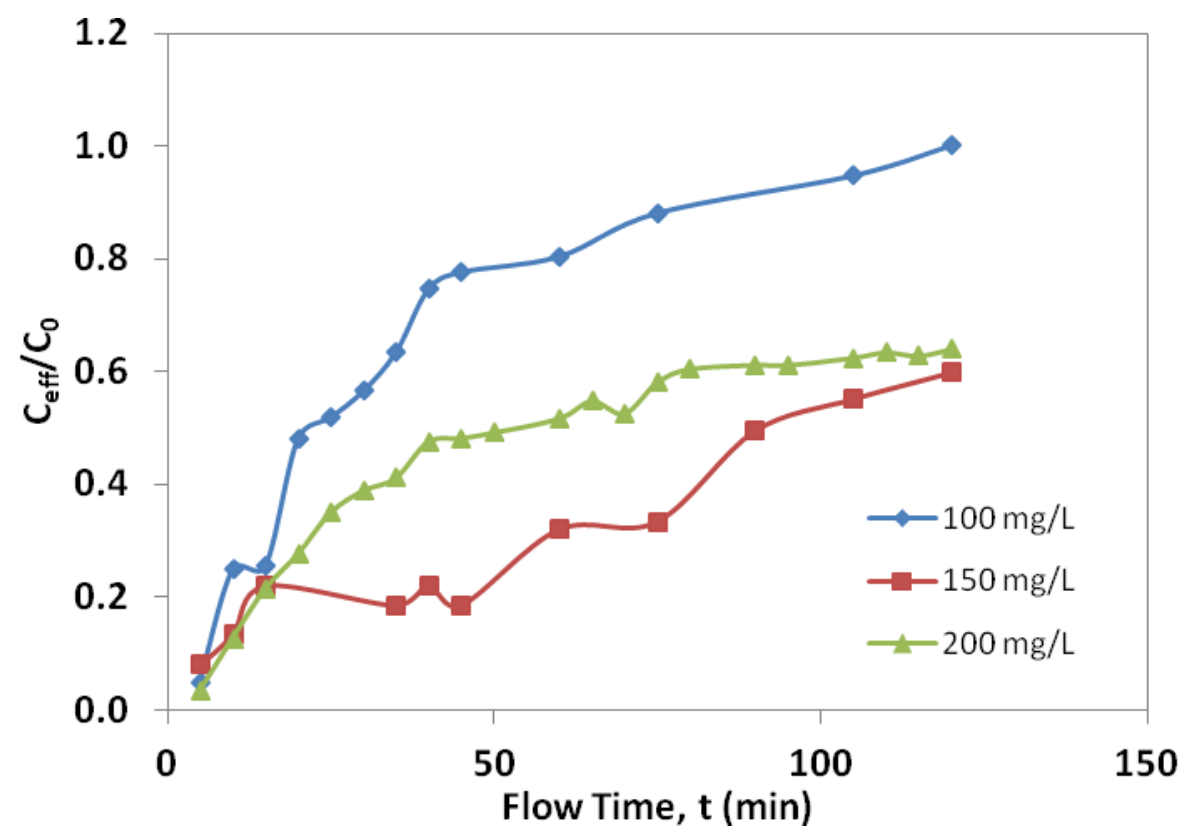

Figure 4. Breakthrough curve for Cd (II) adsorption on prepared AC at different influent concentrations (bed height $=5.5 \mathrm{~cm}$, flow rate $=3.0 \mathrm{~mL} / \mathrm{min}$ )

\subsection{Adsorption modeling for breakthrough curve}

\subsubsection{Thomas model}

The column adsorption data were fitted to the Thomas model in order to evaluate the relationship of the column parameters. The plot was used to determine the Thomas kinetic coefficient $\left(\mathrm{k}_{\mathrm{Th}}\right)$ and the maximum solid-phase concentration of the solute $\mathrm{q}_{\mathrm{O}}(\mathrm{mg} / \mathrm{g})$. From Table 2, the $\mathrm{k}_{\mathrm{Th}}$ values increased while the qo values decreased with the increase in bed height whereas the $\mathrm{k}_{\mathrm{Th}}$ values decreased while the qo values increased with the increase in influent concentration. Meanwhile, both the $\mathrm{k}_{\mathrm{Th}}$ and qo values decreased with the increase in flow rate. The experimental data were better fitted by the Thomas model with longer bed height, slower flow rate and higher influent concentration.

Table 2. Parameters predicted by the Thomas model

\begin{tabular}{ccccccc}
\hline $\begin{array}{c}\text { Bed } \\
\text { Height } \\
(\mathbf{c m})\end{array}$ & $\mathbf{m}(\mathbf{g})$ & $\mathbf{C}_{\mathbf{o}}(\mathbf{m g} / \mathbf{L})$ & $\begin{array}{c}\mathbf{Q} \\
(\mathbf{m L} / \mathbf{m i n})\end{array}$ & $\begin{array}{c}\mathbf{k}_{\mathbf{T h}} \\
(\mathbf{m L} / \mathbf{m i n} . \mathbf{m g})\end{array}$ & $\mathbf{q}_{\mathbf{o}}(\mathbf{m g} / \mathbf{g})$ & $\mathbf{R}^{\mathbf{2}}$ \\
\hline 3.0 & 1.5 & 200 & 3.0 & 0.000126 & 18173.71 & 0.7017 \\
4.0 & 2.1 & 200 & 3.0 & 0.000117 & 14067.16 & 0.8607 \\
5.5 & 3.0 & 200 & 3.0 & 0.000134 & 14947.57 & 0.9587 \\
5.5 & 3.0 & 200 & 2.0 & 0.000127 & 12092.23 & 0.9594 \\
5.5 & 3.0 & 200 & 3.0 & 0.000133 & 16211.28 & 0.9613 \\
5.5 & 3.0 & 200 & 5.0 & 0.000078 & 7463.675 & 0.9686 \\
5.5 & 3.0 & 100 & 3.0 & 0.000251 & 7677.689 & 0.8766 \\
5.5 & 3.0 & 150 & 3.0 & 0.000145 & 14712.44 & 0.8699 \\
5.5 & 3.0 & 200 & 3.0 & 0.000134 & 14947.57 & 0.9587 \\
\hline
\end{tabular}




\subsubsection{Yoon-Nelson model}

Yoon-Nelson model is a simple theoretical model applied to predict the breakthrough activities. According to Lim and Aris [6], it is suitable for the single component system besides using less column data for the construction of the model values. The rate constant and time required for $50 \%$ adsorbate breakthrough can be predicted by the values of $\mathrm{k}_{\mathrm{YN}}$ and $\tau$. These values can be obtained from the linearized Yoon-Nelson equation. Table 3 shows the parameters predicted by the YoonNelson model at different bed heights, flow rates and influent concentrations. The $\mathrm{k}_{\mathrm{YN}}$ and qo values increased with the increase in bed height whereas the $\mathrm{k}_{\mathrm{YN}}$ and qo values decreased with the increase in flow rate. Meanwhile, the $\mathrm{k}_{\mathrm{YN}}$ values increased whereas the qo values decreased with the increase in influent concentration. The results obtained agreed with the results reported by Lim and Aris [6]. The $50 \%$ of the breakthrough for Cd (II) was predicted at nearly 75 to 99 minutes with the bed height of $5.5 \mathrm{~cm}$ at different flow rates and influent concentrations. The columns however did not achieve 50\% breakthrough after one hour of operation. From the $\mathrm{R}^{2}$ values as shown in Table 3, the Yoon-Nelson model had better fitting for the cadmium adsorption in a longer bed column. Lim and Aris [6] also reported similar findings for Yoon-Nelson model applied for adsorption of cadmium using dead calcareous skeletons.

Table 3. Parameters predicted by the Yoon-Nelson model

\begin{tabular}{ccccccc}
\hline $\begin{array}{c}\text { Bed } \\
\text { Height } \\
(\mathbf{c m})\end{array}$ & $\mathbf{m}(\mathbf{g})$ & $\mathbf{C}_{\mathbf{o}}(\mathbf{m g} / \mathbf{L})$ & $\begin{array}{c}\mathbf{Q} \\
(\mathbf{m L} / \mathbf{m i n})\end{array}$ & $\mathbf{K}_{\mathbf{Y N}}\left(\mathbf{m i n}^{-\mathbf{1}}\right)$ & $\boldsymbol{\tau}(\mathbf{m i n})$ & $\mathbf{R}^{\mathbf{2}}$ \\
\hline 3.0 & 1.5 & 200 & 3.0 & 0.0251 & 45.434 & 0.7017 \\
4.0 & 2.1 & 200 & 3.0 & 0.0234 & 49.235 & 0.8607 \\
5.5 & 3.0 & 200 & 3.0 & 0.0267 & 74.738 & 0.9587 \\
5.5 & 3.0 & 200 & 2.0 & 0.0253 & 90.692 & 0.9564 \\
5.5 & 3.0 & 200 & 3.0 & 0.0266 & 81.056 & 0.9613 \\
5.5 & 3.0 & 200 & 5.0 & 0.0156 & 22.391 & 0.9686 \\
5.5 & 3.0 & 100 & 3.0 & 0.0251 & 76.777 & 0.8766 \\
5.5 & 3.0 & 150 & 3.0 & 0.0217 & 98.083 & 0.8699 \\
5.5 & 3.0 & 200 & 3.0 & 0.0267 & 74.738 & 0.9587 \\
\hline
\end{tabular}

\subsubsection{Adam-Bohart model}

Adam-Bohart model is used to predict the breakthrough activities for initial part of the adsorption process. This model uses bed depth, bed area and flow rate of the column system to predict the column performance parameters, including the maximum saturation concentration of the metals, $\mathrm{N}_{\mathrm{O}}$, and the rate constant of Adam-Bohart model, $\mathrm{k}_{\mathrm{AB}}$. From Table 4, the $\mathrm{k}_{\mathrm{AB}}$ values increased while the $\mathrm{N}_{\mathrm{O}}$ values decreased with the increase in bed height. Meanwhile, the $\mathrm{k}_{\mathrm{AB}}$ values decreased while the $\mathrm{N}_{\mathrm{O}}$ values increased with the increase in flow rate and influent concentration. The value of $\mathrm{N}_{O}$ decreased with the increase of bed height as more sites were available for Cd (II) ions adsorption. Meanwhile, the increase in flow rate and influent concentration also increased the $\mathrm{N}_{O}$ values. This was because higher amount of metal ions attached to the sites were available during the adsorption. The Adam-Bohart model was overall fitted better with slower flow rate and longer bed height. 
Table 4. Parameters predicted by the Adam-Bohart model

\begin{tabular}{ccccccc}
\hline $\begin{array}{c}\text { Bed } \\
\text { Height } \\
(\mathbf{c m})\end{array}$ & $\begin{array}{c}\mathbf{U}_{\mathbf{o}} \\
(\mathbf{c m} / \mathbf{m i n})\end{array}$ & $\mathbf{C}_{\mathbf{o}}(\mathbf{m g} / \mathbf{L})$ & $\begin{array}{c}\mathbf{Q} \\
(\mathbf{m L} / \mathbf{m i n})\end{array}$ & $\begin{array}{c}\mathbf{k}_{\mathbf{A B}} \\
(\mathbf{L} / \mathbf{m i n} . \mathbf{m g})\end{array}$ & $\mathbf{N}_{\mathbf{O}}(\mathbf{m g} / \mathbf{L})$ & $\mathbf{R}^{\mathbf{2}}$ \\
\hline 3.0 & 3.8197 & 200 & 3.0 & 0.0000450 & 32628.81 & 0.6828 \\
4.0 & 3.8197 & 200 & 3.0 & 0.0000435 & 25414.24 & 0.9330 \\
5.5 & 3.8197 & 200 & 3.0 & 0.0000910 & 16300.74 & 0.8993 \\
5.5 & 2.5465 & 200 & 2.0 & 0.0000770 & 13045.04 & 0.9543 \\
5.5 & 3.8197 & 200 & 3.0 & 0.0000915 & 17296.28 & 0.9035 \\
5.5 & 6.3662 & 200 & 5.0 & 0.0000260 & 35147.56 & 0.9338 \\
5.5 & 3.8197 & 100 & 3.0 & 0.0001570 & 8785.111 & 0.8426 \\
5.5 & 3.8197 & 150 & 3.0 & 0.0000993 & 15116.4 & 0.9054 \\
5.5 & 3.8197 & 200 & 3.0 & 0.0000910 & 16300.74 & 0.8993 \\
\hline
\end{tabular}

\subsubsection{Bed Depth Time Service (BDST) model}

The BDST model shows the relationship between the service time of the column and the fixed-bed column. This model assumes that the adsorption kinetics is controlled by the surface chemical reaction between the Cd (II) ions in the solution and the oil palm shell-based AC that have not been used, neglecting the intraparticular diffusion and external mass resistance [11]. Figure 5 shows the plot of service time against bed depth at flow rate of $3 \mathrm{~mL} / \mathrm{min}$ and influent concentration of $200 \mathrm{mg} / \mathrm{L}$. The rate constant, $\mathrm{k}_{\mathrm{BDST}}$ and the adsorption capacity per volume, $\mathrm{N}_{\mathrm{O}}$ were predicted to be $0.02157 \mathrm{~L} / \mathrm{mgh}$ and $1.247 \mathrm{mg} / \mathrm{L}$, respectively. The service time increased pseudo exponentially with increasing bed depth, indicating that greater bed height would have longer lifespan, thus requiring longer interval for activated carbon replacement.

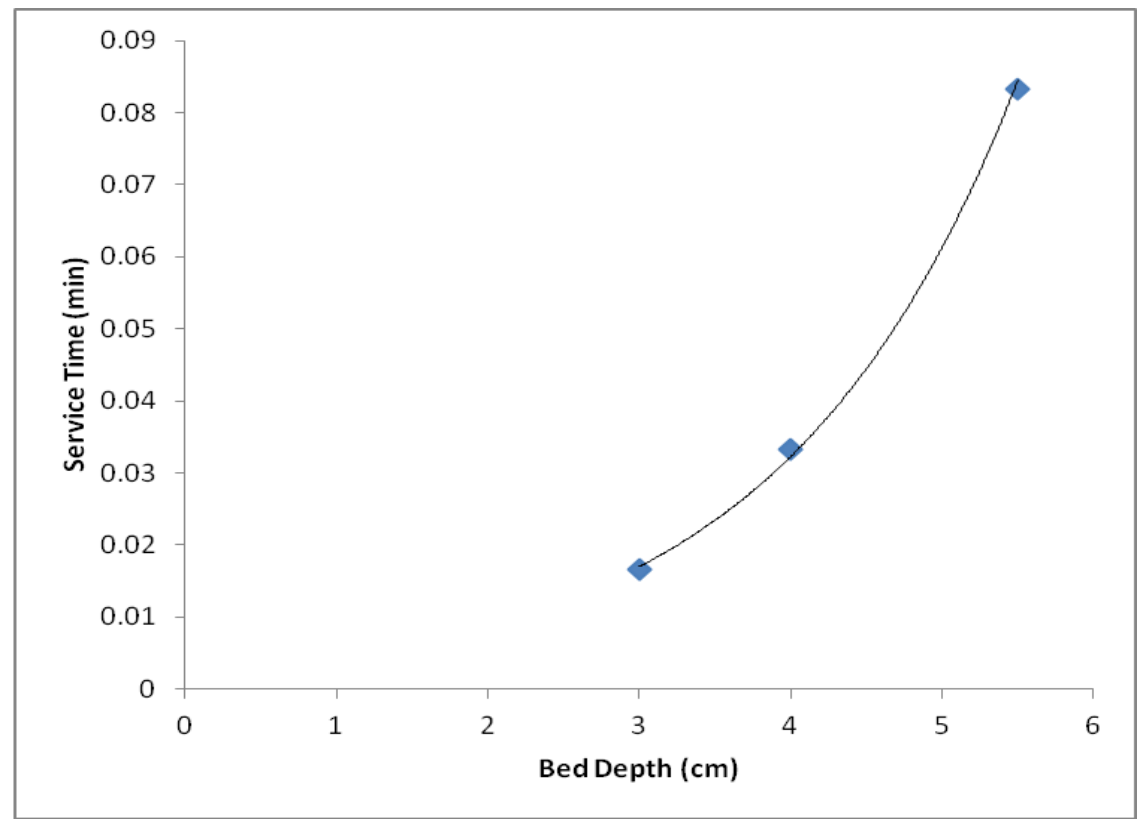

Figure 5. Adsorption modeling using BDST model for adsorption of cadmium onto the prepared AC

\subsubsection{Comparison between the adsorption modeling}

From the experimental data obtained in this study, the strengths and weaknesses of each model studied were evaluated and summarized in Table 5. Thomas, Yoon-Nelson and Adam-Bohart 
models were best fitted for column data with the longest bed height. The column behaviors could be used for prediction in further design implications and improvement works through the models. The four models used in this study were suitable for single component adsorption. The Thomas model provided information about the mass transfer between the cadmium solutions and the oil palm shellbased $\mathrm{AC}$, indicating the driving force under different parameters. The experimental data for adsorption of Cd (II) on the AC agreed well with the theoretical data obtained from the Thomas and Yoon-Nelson models. The four models applied in this study required different parameters for theoretical calculations.

Out of the four models, the Yoon-Nelson model required the least parameters and theoretical data calculation. Yoon-Nelson model provided the mathematical application directly and the information of 50\% column breakthrough, which enabled the prediction of exhaustion period of the column without a long duration of experimental time. The Adam-Bohart model could be used to predict the adsorption capacity of the adsorbent. The results obtained from the Adam-Bohart model could be used in application for a large scale effluent treatment system [6]. However, it required more parameters and calculation to obtain the modeling data. As for BDST model, it is a simple and straight-forward model. However, it could only determine the relationship between the bed depth and the service time.

Table 5. Strengths and weaknesses of the column adsorption models

\begin{tabular}{clrl}
\hline Model & \multicolumn{2}{c}{ Strength } & \multicolumn{2}{c}{ Weakness } \\
\hline Thomas & $\begin{array}{l}\text { Best fitting for longer bed height, } \\
\text { lower flow rate and higher } \\
\text { influent concentration }\end{array}$ & $\begin{array}{l}\text { Not well-described for shorter } \\
\text { column }\end{array}$ \\
\hline Yoon-Nelson & $\begin{array}{l}\text { Less parameters required for } \\
\text { calculation }\end{array}$ & $\begin{array}{l}\text { Not well-fitted for shorter bed depth } \\
\text { of adsorbent }\end{array}$ \\
\hline Adam-Bohart & $\begin{array}{l}\text { Provides the prediction for } \\
\text { saturation concentration } \\
\text { adsorbate }\end{array}$ & $\begin{array}{l}\text { Requires more parameters for model } \\
\text { application }\end{array}$ \\
\hline BDST & Simple model & Only studies the effect of bed depth \\
\hline
\end{tabular}

\section{Conclusion}

The parameters applied in the present study showed the influence on the breakthrough for cadmium ion adsorption. The increase in bed height increased the amount of adsorbent used thus increasing the total removal of Cd (II) removed and prolonged the lifespan of the activated carbon column. However, the increase in flow rate and influent concentration resulted in the shortened lifespan of the column. The column system with bed height of $5.5 \mathrm{~cm}$, flow rate of $2.0 \mathrm{~mL} / \mathrm{min}$ and $200 \mathrm{mg} / \mathrm{L}$ influent concentration showed the best uptake performance in this study. The Thomas model showed a good correlation with the experimental data for Cd (II) adsorption with the longest bed depth. The Yoon-Nelson model estimated the 50\% breakthrough curve with less data required and provided the estimated breakthrough time for the column. The fixed-bed Cd (II) adsorption data were best fitted by the Thomas model and Yoon-Nelson model for the longest bed depth of $5.5 \mathrm{~cm}$, all flow rates studied and highest influent concentration of $200 \mathrm{mg} / \mathrm{L}$ with correlation coefficient greater than 0.95 . This study shows the potential of oil palm shell-derived activated carbon for the application in the removal of Cd (II) ions from aqueous solutions in the form of a barrier. 


\section{Acknowledgements}

The authors acknowledge the research grant provided by Universiti Malaysia Sarawak under Special Grant Scheme F02/SpGS/1406/16/7.

\section{References}

[1] Vignola, R., Bagatin, R., D’Auris, A. D. F., Flego, C., Nalli, M., Ghisletti, D., Millini, R.and Sisto, R. (2011). Zeolites in a permeable reactive barrier (PRB): One year of field experience in a refinery groundwater-Part 1: The performances, Chem. Eng. J. 178, 204-209.

[2] Bortone, I., Chianese, S., Di Nardo, A., Di Natale, M., Erto, A. and Musmarra, D. (2013). A Comparison Between Pump \& Treat Technique and Permeable Reactive Barriers for the Remediation of Groundwater Contaminated by Chlorinated Organic Compounds, AIDIC Conference Series, 11, 6170 .

[3] Shafie, S. M., Mahlia, T. M. I., Masjuki, H. H. and Yazid, A. A. (2012). A review on electricity generation based on biomass residue in Malaysia, Renew. Sustain. Energ. Rev. 16, 5870-5889.

[4] Chan, J. C. (2014). Adsorption of Cadmium using Phosphoric Acid Treated Microwave-induced Oil Palm Shell Based Activated Carbon, Final Year Project Dissertation, Universiti Malaysia Sarawak, Malaysia.

[5] Baig, S. A., Zhu, J., Tan, L., Xue, X., Sun, C. and Xu, X. (2014). Influence of calcination on magnetic honeycomb briquette cinders composite for the adsorptive removal of As (III) in fixed-bed column, Chem. Eng. J. 257, 1-9.

[6] Lim, A. P. and Aris, A. Z. (2014). Continuous fixed-bed column study and adsorption modeling: Removal of cadmium (II) and lead (II) ions in aqueous solution by dead calcareous skeletons, Biochem. Eng. J. 87, 50-61.

[7] Sotelo, J. L., Ovejero, G., Rodriguez, A., Alvarez, S. and Garcia, J. (2013). Analysis and modelling of fixed bed column operations on flumequine removal onto activated carbon: $\mathrm{pH}$ influence and desorption studies, J. Chem. Eng. 228, 102-113.

[8] Hasfalina, C.M., Maryam, R.Z., Luqman, C.A. and Rashid, M. (2012). Adsorption of copper (II) from aqueous medium in fixed-bed column by Kenaf fibres, APCBEE Procedia 3, 255-263.

[9] Salehi, P., Asghari, B. and Mohammadi, F. (2010). Biosorption of Ni (II), Cu (II) and Pb (II) by Punica geranatum from aqueous solutions, J. Water Res. Protect. 2 (8), 701-705.

[10] Tan, I.A.W. (2008). Preparation, characterization and evaluation of mesoporous activated carbons derived from agricultural by-products for adsorption of methylene blue and 2,4,6-trichlorophenol, $\mathrm{PhD}$ Dissertation, University Science Malaysia.

[11] Taty-Costodes, V.C., Fauduet, H., Porte, C. and Ho, Y.S. (2005). Removal of lead (II) ions from synthetic and real effluents using immobilized Pinus sylvestris sawdust: Adsorption on a fixed-bed column, J. Hazard. Mater. B123, 135-144. 